\title{
Effects of lead exposure on alpha-synuclein and p53 transcription
}

\author{
Pei-Jun Zuo ${ }^{1}$, A. Bakr M. Rabie ${ }^{1}$ \\ ${ }^{1}$ Faculty of Dentistry, the University of Hong Kong, Hong Kong SAR. Correspondence should be addressed to Peijun Zuo (pzuo@hkucc.hku.hk). \\ Received Nov. $1^{\text {st }}, 2008$; revised Feb. 19 $9^{\text {th }}, 2009$; accepted Feb. $23^{\text {rd }}, 2009$
}

\begin{abstract}
Objective: Epidemiological studies have found that lead exposure increases the risk for Parkinson's disease and patients with Parkinson's disease have lower odds of developing nonsmoking-related cancer (1). It would be interesting therefore to find the molecular links between Parkinson's disease and cancer. To do this, we studied mRNA expression of alphasynuclein gene, a promising genetic marker for Parkinson's disease, and expression of the tumor suppressor gene p53 after oxidative stress induced by lead. Methods: We used ATDC 5 cell line as a model of tumor and treated by lead nitrate for $0,2,4,16,24$ and 48 hours. The mRNAs of alpha-synuclein and p53 were quantified by reverse transcriptase polymerase chain reaction and expressed as mean ( $\pm S D$ ) for 3 samples at each time point. Results: Expression of both of alpha-synuclein and p53 mRNA increased with increasing exposure of lead treatment. The levels of alpha-synuclein and p53 mRNA were correlated with each other $(r=0.9830 ; \mathrm{P}<0.001)$. Conclusion: We propose that lead's neurotoxicity in PD is caused by alpha-synuclein expression and aggregation, which releases the inhibitory influence of alpha-synuclein on p53 expression, thereby allowing p53 to act as the cell's guardian of the genome and reduce tumorigenic potential. Treatments that reduce alpha-synuclein aggregation may need to account for a concomitant reduction in p53's protective effect.
\end{abstract}

Keywords: Alpha-synuclein, p53, Real-time PCR, ATDC5, Aging, Cancer

\section{INTRODUCTION}

Parkinson's disease (PD) typically affects people aged 50 years and older, and the risk of disease increases with age. A promising diagnostic marker for PD is alphasynuclein (2), which is the primary structural component of inclusion bodies (Lewy bodies) that are found in the neurons of patients with PD. Interestingly, epidemiological evidence shows that individuals with PD have reduced odds for many common types of non-smokingrelated cancers (1). However, it is not known if this finding indicates a direct association between the two diseases, such as a reduced risk of non-smoking-related cancer among patients who develop PD, or a reduced risk of developing PD or other age-related neurodegenerative diseases among individuals with non-smokingrelated cancer. It would therefore be interesting to study the possible biological and molecular links between agerelated neurodegenerative diseases such as PD and cancer, especially because cancer is often also regarded as a disease of aging. The findings would provide important information on the mechanisms underlying normal and abnormal developmental and ageing processes. The $\mathrm{p} 53$ tumor suppressor protein may be one such link because hyperactivation of p53 in mice has been shown to increase resistance to spontaneous tumorigenesis while apparently accelerating aging (3). Cancer and neurodegenerative diseases might also be interrelated at the etiologic or environmental level: occupational exposure to lead is a risk factor for PD (4), while lead can be carcinogenic in rodents and genotoxic in fish (5), and it can also induce cell apoptosis via p53 (6).

To investigate the possible link between lead exposure and expression of alpha-synuclein and p53, we used a lead-sensitive cell culture model. We selected the ATDC5 cell line because it is an established mouse embryonic carcinoma-derived cell line that has both carcinogenic and chondrogenic properties (7). Not only does this cell line have chondroprogenitor potential and produce chondrocyte-specific extracellular matrix when stimulated by insulin, but it can also proliferate rapidly in the presence of fetal bovine serum (8). Expression levels of alpha-synuclein and p53 were thus measured at the mRNA level after treatment of cells with lead nitrate.

\section{EXPERIMENTAL PROCEDURES}

Cell Culture -The ATDC5 cells were cultured in a 1:1 mixture of Dulbecco's modified Eagle's medium and Ham's F-12 medium (Flow Laboratories, Irvine, UK) containing 5\% fetal bovine serum (GIBCO BRL, Gaithersburg, MD), $100 \mathrm{U} / \mathrm{mL}$ penicillin, and $100 \mu \mathrm{g} /$ $\mathrm{mL}$ streptomycin (Biofluids Inc., Rockville, MD, USA) 
and then incubated at $37^{\circ} \mathrm{C}$ in a humidified atmosphere containing $5 \%$ carbon dioxide. An inoculum of cells $\left(10^{4}\right.$ per $\mathrm{mL}$ in $\left.30 \mathrm{~mL}\right)$ was transferred to each of 7 Petri dishes. Lead nitrate was added to the cells. The final concentration of the lead nitrate per dish was 200 $\mu \mathrm{mol} / \mathrm{L}$. For increasing the solubility of lead nitrate, glutamic acid was added to medium in equimolar amounts of the lead nitrate. The cells were harvested at times of $0,2,4,16,24$ and 48 hours.

Reverse Transcriptase Polymerase Chain Reaction Analysis- Total RNA was isolated from cells by using an RNeasy Mini Kit (Qiagen Sciences, Germantown, $\mathrm{MD})$ according to the manufacturer's instructions. Reverse transcription of the mRNA was performed with oligo-(dT) primers and MulV reverse transcriptase (Applied Biosystems, Foster City, CA). Polymerase chain reaction (PCR) was then done in a StepOne Real-Time PCR System (Applied Biosystems); each 20- $\mu \mathrm{L}$ sample contained Power SYBR Green PCR Master Mix (Applied Biosystems), $40 \mathrm{ng}$ of complementary DNA, and the pairs of primers listed in Table 1 . The cycling profiles were as follows: $95^{\circ} \mathrm{C}$ for 10 minutes, $95^{\circ} \mathrm{C}$ for 15 seconds and $60^{\circ} \mathrm{C}$ for 1 minute (for 40 cycles). Samples were run concurrently with standard curves derived from PCR products, and serial dilutions were performed to obtain appropriate template concentrations.

Mouse $\beta$-actin was used as an example of a leadinsensitive house-keeping protein and thus its primer acted as a negative control to correct for RNA recovery and reverse transcription efficiency. The mRNA concentrations were determined by by optical density at $\lambda 260 / 280$ and were standardized at each time point to mouse $\beta$-actin mRNA concentrations.

Statistical Analysis- Data were expressed as mean \pm SD for 3 or more replicates per sample, in arbitrary units relative to the mRNA level of $\beta$-actin. The student $t$ test was used to evaluate differences between groups. Differences were considered significant at a level of $\mathrm{p}<0.05$.

\section{RESULTS}

Alpha-synuclein mRNA- Lead exposure induced a 50\% increase in alpha-synuclein mRNA expression in ATDC5 cells at 2 hours (Figure 1). The mRNA level further increased by about $20 \%$ between 2 hours and 16 hours, remained the same between 16 and 24 hours and then increased rapidly to 3 times the 24-hour level at 48 hours. The results thus show that the expression of alpha-synuclein was significantly increased by the expo-

Table 1. List of primers

\begin{tabular}{ll} 
Primer & Sequence (sense/antisense) \\
\hline Alpha-synuclein & 5'- AGT GGA GGG AGC TGG GAA TA \\
& TAG-3' \\
& 5'-TCC TCA CCC TTG CCC ATC T-3' \\
p53 & 5'-AGC GCT GCT CCG ATG GT-3' \\
& 5'-TTC CTT CCA CCC GGA TAA GA-3' \\
Mouse $\beta$-actin & 5'-GGC CAA CCG TGA AAA GAT GA-3' \\
& 5'-CAG CCT GGA TGG CTA CGT ACA-3' \\
\hline
\end{tabular}

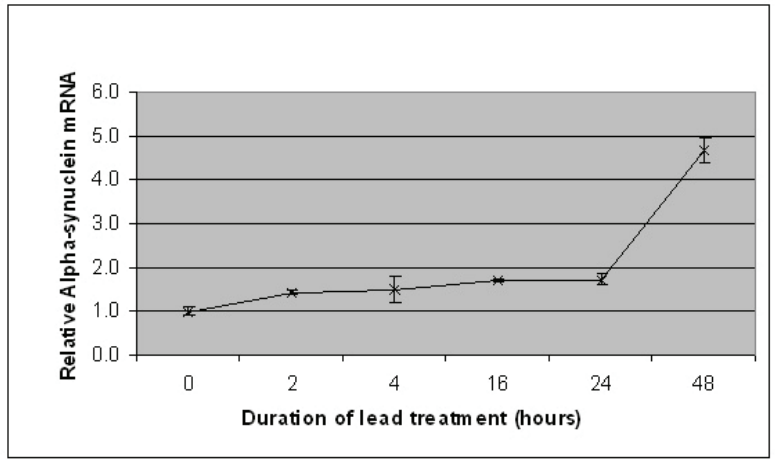

Figure 1. Alpha-synuclein mRNA in ATDC5 cells. ATDC5 cells were treated with $200 \mu \mathrm{M}$ lead nitrate for duration of $0,2,4,16$, 24 and 48 hours. The results as expressed as mean \pm SD Psmc3 mRNA amount relative to beta-actin for three samples.

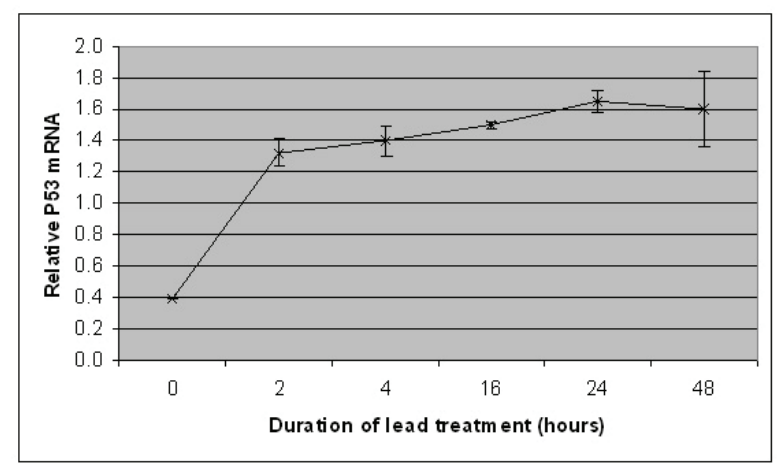

Figure 2. p53 mRNA in ATDC5 cells. ATDC5 cells were treated with $200 \mu \mathrm{M}$ lead nitrate for duration of $0,2,4,16,24$ and 48 hours. The results as expressed as mean \pm SD p53 mRNA amount relative to beta-actin for three samples.

sure time.

p53 mRNA- Expression of p53 mRNA in ATDC5 cells was also significantly increased by the exposure time. By 2 hours, lead exposure had rapidly increased the p53 mRNA level to more than 3.4 times the basal amount. (Figure 2) There was a moderate further increase in mRNA expression between 2 and 24 hours, by about $25 \%$, and then expression decreased very slightly at 48 hours, but the decrease was not statistically significant. The rising trend in p53 mRNA level with an increase in exposure time was similar to that of alpha-synuclein mRNA. The levels of alpha-synuclein and p53 mRNA were correlated with each other $(\mathrm{r}=0.9830 ; \mathrm{P}<0.001)$.

\section{DISCUSSION}

We have demonstrated that expression of alphasynuclein and p53 mRNA increased with increasing duration of lead exposure in ATDC5 cells and that there was a correlation between alpha-synuclein and p53 mRNA expression after lead treatment. Although we did not examine the expression or localization of the corresponding proteins, our findings suggest that alphasynuclein and p53 expression are stimulated by lead treatment in a coordinated way, which may reflect a shared cellular response to biological effects of lead exposure such as neurotoxicity, genotoxicity and oxida- 
tive stress. In this study, alpha-synuclein was assumed to be a marker of increased likelihood of PD development and p53 was a marker of decreased cancer potential. Our results thus suggest a molecular mechanism for the inverse epidemiological association observed between PD and cancer (1).

Alpha-synuclein aggregation appears to play a major role in Lewy body formation and PD (9) (10), and occupational exposure to lead is a risk factor for PD (4). In addition, lead can form inclusion bodies in renal cells of poisoned humans or animals (11) and lead is a known potent neurotoxicant. Evidence indicates that lead exposure early in life may later on cause neurodegenerative disease such as Alzheimer's disease (12). Indeed, Alzheimer's disease is similar to PD, in that both are caused by a progression of amyloidogenesis in the brain. The link between alpha-synuclein and p53 expression on lead exposure demonstrated in this study suggests that alpha-synuclein protein expression and aggregation in cells can be stimulated by lead and contribute to inclusion body formation seen in cells of PD patients, while p53 protein accumulates to prevent cellular and genetic damage due to increased oxidative stress.

Because the p53 transcription factor regulates the cell cycle and apoptosis, it has been described as "the guardian of the genome," referring to its tumor suppressor role in conserving genomic stability by preventing the accumulation of mutations (13). An increase in p53 expression during lead exposure would result in an increased likelihood of cell cycle arrest to allow for genomic repair, or apoptosis if the genome is irreparable, and a similar mechanism might explain the possible lowered risk of tumorigenesis among PD patients. Indeed, lead can induce cell apoptosis via p53 in culture cells (6), and doing so would decrease the genotoxic potential of lead and hence the likelihood of cancer transformation. Another known role of p53 is to induce differentiation, which is another potential mechanism for preventing tumorigenesis. Interestingly, lead ion $\left(\mathrm{Pb}^{2+}\right)$-induced neurotoxicity may also be partially mediated through p53-independent apoptosis that is enhanced by glutamate (14), thereby again lowering tumorigenic potential.

A link between alpha-synuclein and p53 function has been previously demonstrated. In neuronal cell cultures, alpha-synuclein reduced the ability of cells to apoptose with and without the apoptotic trigger of staurosporine, and also reduced p53 expression and transcriptional activity (15). Both of the p53 expression and transcriptional activity was tested 48 hours after transfection. However, the dopamine-derived drug 6-hydroxydopamine reversed these effects and increased alphasynuclein aggregation. The present data indicated p53 transcriptional activity was increased in 48 hours as well as alpha-synuclein transcriptional activity after lead treatment. Although we did not test for apoptotic status and immunoreactivity in our study, it is conceivable that alpha-synuclein has an effect on p53 expression and function and that lead treatment promotes alphasynuclein aggregation, thereby resulting in p53 expression and related downstream cellular events. This series of events may explain lead's neurotoxicity and parallels the proposed role of the natural toxin 6hydroxydopamine in alpha-synuclein aggregation in the etiology of PD (15).

The biological mechanism connecting alphasynuclein, p53, lead exposure, PD and cancer does not appear to be simple. Epidemiological studies have shown that the odds of only non-smoking-related, but not smoking-related, cancer were lowered among patients with PD (1). The paradox is that smoking increases a human's intake of lead. Yet, there is a weak association between stomach and lung cancer frequency and an individual's exposure to lead (16), and a small but statistically significant increase in mortality has been found among employees at lead battery plants and lead smelters (17). In contrast, these employees' mortality from kidney cancer, bladder cancer, cancer of the central nervous system, lymphatic cancer and hematopoietic cancer was not increased (17). Finally, although both PD and cancer can be viewed as diseases of aging, laboratory studies have reported that p53 can uncouple cancer and aging by regulating both in a mutually exclusive way-namely, p53 hyperactivation in mice reduced the risk of spontaneous cancer but accelerated organismal aging (3). Organismal aging may be related by p53's ability to induce apoptosis and, on prolongued activation, to induce cellular terminal cell cycle block or "senescence," and may be controlled by subcellular localization (18). We will use of a neuronal cell line to do assays for protein expression, phenotypes such as apoptosis, differentiation, cell division, cell cycle, etc give better information.

Our findings provide some insight into the association between PD and cancer, and the behavior of cells in response to lead exposure. We propose that lead's neurotoxicity in PD is caused by alpha-synuclein expression and aggregation, which releases the inhibitory influence of alpha-synuclein on p53 expression and allows p53 to act as the cell's guardian of the genome, thereby reducing tumorigenic potential. It is possible that in the absence of lead, other triggers of alpha-synuclein expression and aggregation are involved in promoting p53 expression in the etiology of PD and other age-related neurodegenerative diseases. The results also suggest that treatments for PD based on preventing alpha-synuclein aggregation need to take into account the possible side effect of reducing p53 expression and function, and increasing tumorigenic potential. Treatments for cancer based on p53 expression also need to take into account the side effect of aging if p53 is allowed to be hyperactivated.

\section{DISCLOSURE STATEMENT}


The authors have declared that no competing interests exist.

\section{ACKNOWLEDGMENTS}

The authors thank Dr. Trevor Lane for critical evaluation of this manuscript. This research was supported by research grant of Professor Dr. A. Bakr M. Rabie.

\section{REFERENCES}

[1] A. B. West, V. L. Dawson and T. M. Dawson, (2005) Trends Neurosci 28, 348-352.

[2] O. M. El-Agnaf, S. A. Salem, K. E. Paleologou, M. D. Curran, M. J. Gibson, J. A. Court, M. G. Schlossmacher and D. Allsop, (2006) FASEB J 20, 419-425.

[3] S. D. Tyner, S. Venkatachalam, J. Choi, S. Jones, N. Ghebranious, H. Igelmann, X. Lu, G. Soron, B.Cooper, C. Brayton, S. Hee Park, T.Thompson, G. Karsenty, A. Bradley, and L. A. Donehower, (2002) Nature 415, 45-53.

[4] S. Coon, A. Stark, E. Peterson, A. Gloi, G. Kortsha, J. Pounds, D. Chettle and J. Gorell, (2006) Environ Health Perspect 114, $1872-1876$.

[5] A. G. Osman, I. A. Mekkawy, J. Verreth, S. Wuertz, W. Kloas, and F. Kirschbaum, (2008) Environ Toxicol.
[6] J. Xu, L. D. Ji and L. H. Xu, (2006) Toxicol Lett 166, 160-167.

[7] T. Atsumi, Y. Miwa, K. Kimata and Y. Ikawa, (1990) Cell Differ Dev 30, 109-116.

[8] C. Shukunami, C. Shigeno, T. Atsumi, K. Ishizeki, F. Suzuki and Y. Hiraki, (1996) J Cell Biol 133, 457-468.

[9] P. Jenner and C. W. Olanow, (1998) Ann Neurol 44, S72-84.

[10] W. Zhou and C. R. Freed, (2004) J Biol Chem 279, 1012810135.

[11] W. Qu, B. A. Diwan, J. Liu, R. A. Goyer, T. Dawson, J. L. Horton, M. G. Cherian and M. P. Waalkes, (2002) Am J Pathol 160, 1047-1056.

[12] L. D. White, D. A. Cory-Slechta, M. E. Gilbert, E. TiffanyCastiglioni, N. H. Zawia, M. Virgolini, A. Rossi-George, S. M. Lasley, Y. C. Qian and M. R. Basha, (2007) Toxicol Appl Pharmacol 225, 1-27.

[13] S. Bates, A. C. Phillips, P. A. Clark, F. Stott, G. Peters, R. L. Ludwig and K. H. Vousden, (1998) Nature 395, 124-125.

[14] J. Loikkanen, K. Chvalova, J. Naarala, K. H. Vahakangas and K. M. Savolainen, (2003) Toxicol Lett 144, 235-246.

[15] C. Alves Da Costa, E. Paitel, B. Vincent and F. Checler, (2002) J Biol Chem 277, 50980-50984.

[16] H. Fu and P. Boffetta, (1995) Occup Environ Med 52, 73-81.

[17] O. Wong and F. Harris, (2000) Am J Ind Med 38, 255-270.

[18] J. Wesierska-Gadek and G.Schmid, (2005) Cell Mol Biol Lett 10, 439-453. 